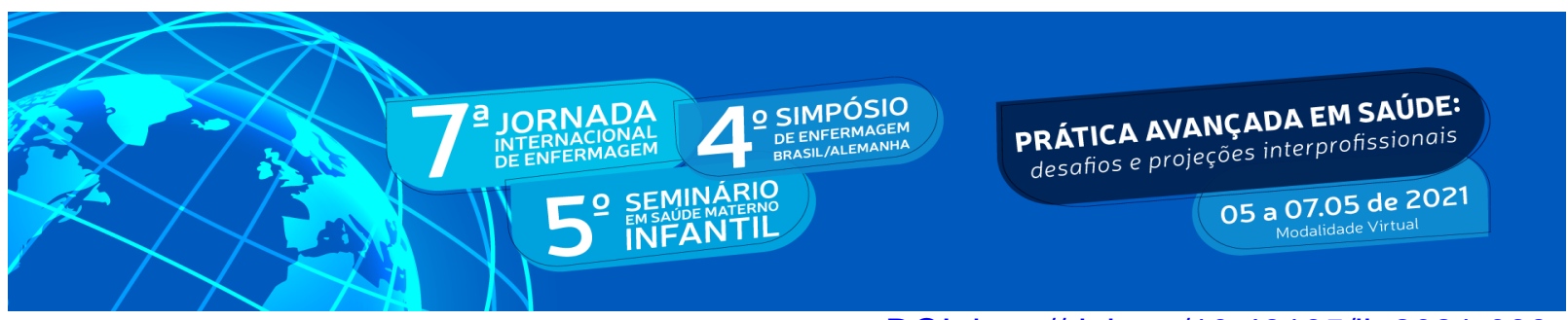

DOI: http://doi.org/10.48195/jie2021-039

\title{
PREENCHIMENTO DA CADERNETA DE SAÚDE DA CRIANÇA: EVIDÊNCIAS NA LITERATURA ${ }^{1}$
}

\section{Carine de Pelegrini Bissacot²; Giovana Luiza Rossato²; Joice Ketes²; Mariana Fogaça Martins $^{2}$; Rosiane Filipin Rangel ${ }^{3}$}

\author{
RESUMO
}

Investigar as evidências na literatura acerca do preenchimento da caderneta de saúde da criança. Trata-se de uma Revisão Narrativa da Literatura, realizada entre fevereiro e março de 2021, nas bases de dados BDENF, LILACS e na Biblioteca Eletrônica SCIELO. Os resultados apresentaram uma consonância diante o preenchimento insatisfatório das Caderneta de Saúde da Criança, despreparo dos profissionais, falhas nas orientações para a família e a percepção do documento como cartão de vacina. Considerando-se as fragilidades na utilização da Caderneta, percebeu-se que é necessário ascender capacitações para os profisssionais de saúde, a fim de compreenderem a importância do seu uso. Assim, refletindo nas orientações para os familiares durante a entrega na maternidade até o acompanhamento em consultas nos demais serviços.

Palavras-chave: Saúde da Criança; Enfermagem; Caderneta de Saúde da Criança; Assistência integral à saúde da criança.

\begin{abstract}
Investigate the evidence in the literature regarding filling out the child's health booklet. This is a Narrative Literature Review, carried out between February and March 2021, in the databases BDENF, LILACS, and in the Electronic Library SCIELO. The results were consistent with the unsatisfactory completion of the Child Health Handbook, the unpreparedness of the professionals, flaws in the guidelines for the family, and the perception of the document as a vaccination card. Considering the weaknesses in the use of the Handbook, it was realized that it is necessary to increase training for health professionals, to understand the importance of its use. Thusly, reflecting on the guidelines for family members during delivery of the document at maternity hospital until the follow-up in consultations at other services.
\end{abstract}

Key Words: Child Health; Nursing; Child Health Handbook; Comprehensive child health care;

\section{INTRODUÇÃO}

\footnotetext{
${ }^{1}$ Trabalho de Pesquisa vinculado ao projeto: Qualificação do acompanhamento multiprofissional de saúde em relação ao crescimento e desenvolvimento infantil na região central do Rio Grande do Sul, aprovado no edital: Chamada Decit/SCTIE/MS-CNPq-FAPERGS no 08/2020, financiado pela Fundação de Amparo à Pesquisa do Estado do Rio Grande do Sul - FAPERGS.

${ }^{2}$ Acadêmica do curso de Enfermagem - UFN, e-mail: cabissacot@gmail.com

${ }^{2}$ Acadêmica do curso de Enfermagem - UFN, e-mail: rossatogiovana@gmail.com

${ }^{2}$ Acadêmica do curso de Enfermagem - UFN, e-mail: kettesioice2@gmail.com

${ }^{2}$ Acadêmica do Curso de Enfermagem - UFN, e-mail: marianaf.martins03@gmail.com

${ }^{3}$ Orientadora. Doutora em Enfermagem. Docente do curso de Enfermagem - UFN, e-mail: rosiane@ufn.edu.br
} 


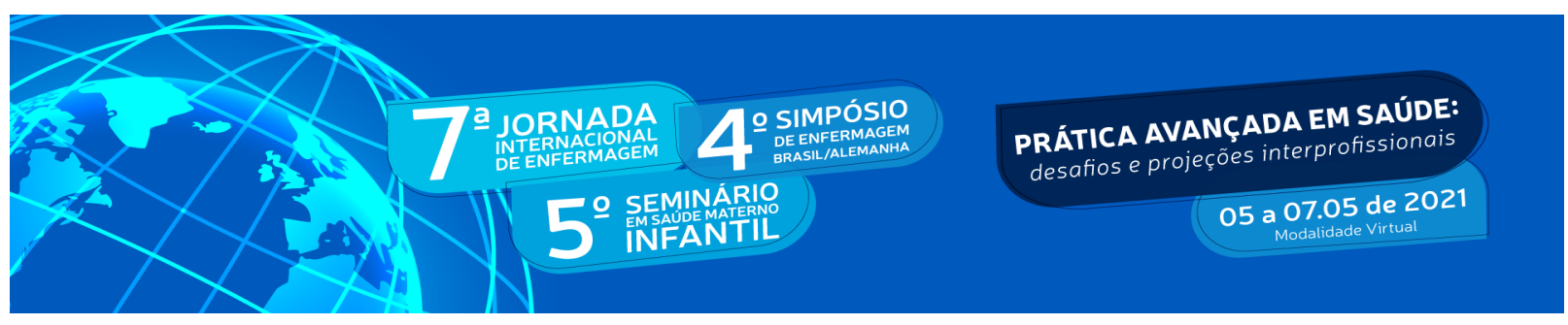

A Política Nacional de Atenção Integral à Saúde da Criança, tem por objetivo proporcionar e preservar a saúde das crianças por meio de ações que visam a atenção integral, desde a gestação até os nove anos de vida. As estratégias são principalmente estabelecidas no Eixo Estratégico III sobre Promoção e acompanhamento do crescimento e desenvolvimento integral, no qual conduz as atividades com a utilização da Caderneta de Saúde da Criança (CSC). Sendo essa, uma ferramenta sobre vigilância e orientações para o crescimento e desenvolvimento infantil necessário (BRASIL, 2018).

A entrega da CSC ocorre na alta da maternidade juntamente com as devidas orientações acerca de sua utilização. Os preenchimentos no qual são cabíveis aos profissionais de saúde, devem ser realizados de modo responsável e completo para que a família acompanhe a saúde da criança. Da mesma forma, servirá para consulta das informações com relação à saúde da criança em todos os contextos de cuidado (BRASIL, 2018).

A CSC teve sua origem a partir do Programa de Atenção Integral à Saúde da Criança (PAISC), criado em 1984 pelo Ministério da Saúde, sendo um marco inicial brasileiro na luta por melhores condições de saúde à população infantil (LEAL et al, 2018). De acordo com suas propostas, foi lançado o cartão da criança, com o intuito de conscientizar a população e introduzir a família na promoção da saúde (SALLES; TORIYAMA, 2017).

Assim, em 2005, realizou-se uma revisão no cartão da criança, no qual acarretou na CSC, trazendo uma nova concepção de vigilância integral à saúde. Já em 2007, o instrumento foi reformulado apresentando novas curvas de crescimento desenvolvidas pela Organização Mundial da Saúde (OMS); e em 2009 foi lançada uma nova versão, semelhante à atual, onde a caderneta foi dividida em duas partes: a primeira para uso do cuidador e a segunda para uso do profissional de saúde, entre outras modificações (ABUD; GAÍVA, 2015).

Em um estudo realizado por Andrade, Rezende e Madeira (2014) com o intuito de analisar a compreensão da importância da CSC pelos profissionais de saúde, pode-se perceber que há uma falha na hora de capacitar e na total compreensão sobre a mesma e seu conteúdo. No estudo citado, foi questionado sobre a concepção dos profissionais, sendo que esses 


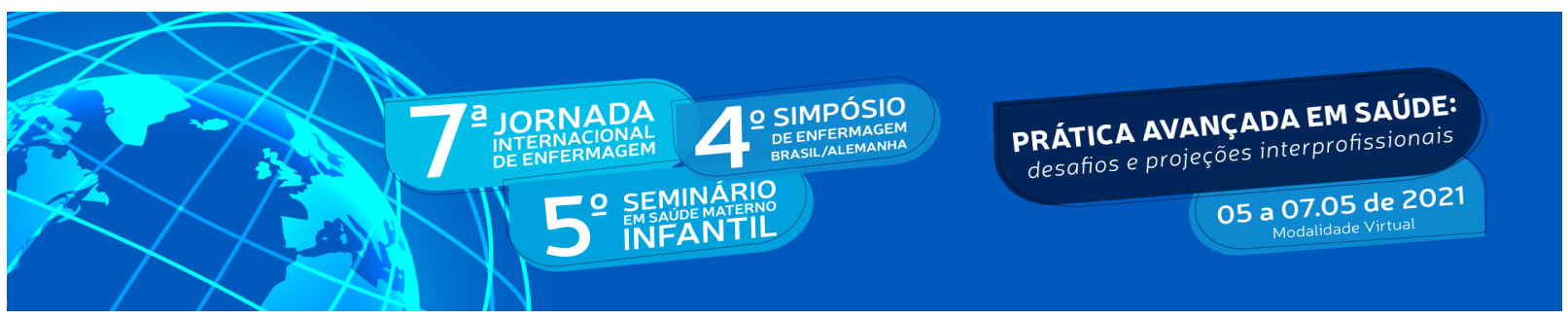

afirmaram compreender a CSC como um instrumento para acompanhar o crescimento da criança e a situação vacinal.

Destacam também que tem dificuldade de manusear diversos conteúdos, devido à sobrecarga e falta de tempo para leitura e estudo da mesma, porém foi destacado que a CSC é uma oportunidade de troca de conhecimento sobre a saúde e vida da criança entre profissionais e família e/ou responsáveis. Fica evidente e explícito no estudo proposto que para o cumprimento da CSC seja satisfatório é fundamental a utilização adequada, de forma que só será alcançada com a capacitação dos profissionais para uma melhor compreensão do instrumento de maneira que se consiga alcançar uma saúde integral da criança (ANDRADE; REZENDE; MADEIRA, 2014; BRANQUINHO; LANZA, 2018).

Por meio da CSC é possível um olhar/assistir pautado na integralidade dessa população, contudo o não preenchimento ou o preenchimento inadequado desse documento interfere no acompanhamento do crescimento e desenvolvimento infantil. Cabe ressaltar que, muitas vezes, a não detecção de algum atraso, que pode ser evidenciado com a ajuda da caderneta, repercute em toda a vida da criança e sua família, trazendo prejuízos no viver saudável e na qualidade de vida. Desse modo, analisar as evidências na literatura acerca do tema, possibilita identificar as lacunas da sua utilização e o desenvolvimento de estratégias para solucioná-las.

\section{OBJETIVO}

Investigar as evidências na literatura acerca do preenchimento da caderneta de saúde da criança.

\section{METODOLOGIA}

Trata-se de uma Revisão Narrativa da Literatura (RNL). A busca do material foi realizada entre os meses de fevereiro a março de 2021, nas bases de dados Literatura Latino-Americana e do Caribe em Ciências da Saúde (LILACS), Base de dados em 


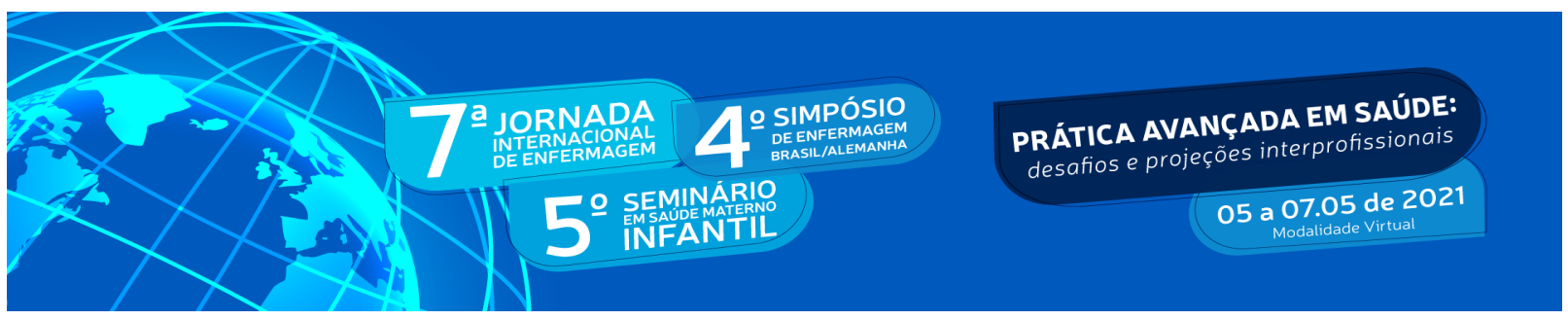

Enfermagem (BDENF) e na Biblioteca Eletrônica Científica Online (SCIELO) por meio das palavras-chave: "saúde da criança" and "Preenchimento da caderneta" and "caderneta".

$\mathrm{Na}$ etapa seguinte realizou-se a seleção dos estudos por meio da aplicação dos critérios de inclusão, quais sejam: artigos no idioma português, dos últimos cinco anos (2016-2020) visando obter dados mais recentes. Os critérios de exclusão foram estudos e pesquisas de anais de congressos, monografias, dissertações, teses e boletins informativos.

Foram selecionados 11 artigos, sendo quatro produções no SCIELO, três produções no LILACS e quatro na BDENF. Após a seleção, foi realizada a leitura na íntegra dos artigos e seus resultados foram agrupados para discussão.

\section{RESULTADOS E DISCUSSÃO}

A CSC surgiu em 2005, a partir da atualização do cartão da criança. Esse documento passou a ser o principal instrumento de acompanhamento e registro sobre dados referentes ao crescimento e desenvolvimento infantil, com o objetivo de avaliações e preenchimentos em todas as consultas para um maior controle, de maneira que fosse necessário este monitoramento desde o nascimento até os três anos de idade com a finalidade de identificação precoce de necessidades especiais (CAMINHA et al, 2017).

Os 1.000 dias críticos compreendidos pelos nove meses de vida fetal até os dois primeiros anos caracterizam-se por um período de fragilidades da criança, onde a sobrevivência e desenvolvimento devem receber uma atenção especial por parte dos profissionais, com um acompanhamento adequado. Ressalta-se que é nos primeiros anos de vida que se encontram os maiores índices de mortalidade infantil devido a doenças em decorrência de processos infecciosos, que com uma vigilância adequada podem ser prevenidas e/ou detectadas precocemente (CAMINHA et al, 2017).

Para Souza et al (2019) o desenvolvimento infantil pode ser descrito como um processo em que a criança passa por uma expansão de habilidades, desde o aspecto físico ou psicológico e socioemocionais, desencadeando assim o aumento da autonomia e independência. $\mathrm{Na}$ infância a criança tem intensa atividade cerebral e desenvolvimento de tamanho corporal, o que reforça a necessidade do acompanhamento do crescimento e 


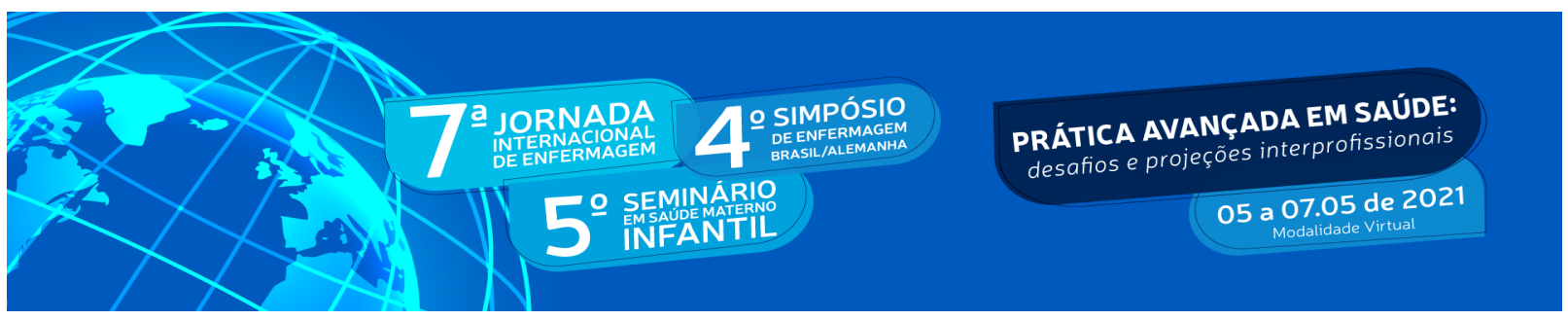

desenvolvimento dos infantes, viabilizando a identificação precoce de possíveis alterações e facilitando intervenções adequadas diminuindo os riscos de morbimortalidade.

Estudo realizado por Reichert et al (2016), trouxe dados estimados que a cada ano, no mundo, cerca de 6,6 milhões de crianças menores de cinco anos morrem por doenças prevalentes na infância e evitáveis se houvesse um melhor acompanhamento delas neste período da vida do infante, reforçando assim a necessidade de uma melhor assistência nesses anos iniciais. Fica inequívoca a importância da prevenção e promoção de saúde na primeira infância, como ferramenta de rastreamento de doenças, atrasos de desenvolvimento e aumento da sobrevida.

Evidencia-se que registros incompletos comprometem a continuidade do cuidado do público infantil, pois passam despercebidas alterações que podem estar sendo identificadas na primeira consulta, perdendo o registro e acompanhamento de informações significativas para que o desenvolvimento infantil ocorra sem maiores preocupações. Informações estas que são contempladas na CSC para serem preenchidas e assim obtenha-se a continuidade e cuidado integral do infante ( ROSOLEM et al, 2019).

Na pesquisa de Freitas et al (2019), no qual foi averiguado sobre o preenchimento da CSC em uma capital da Região Norte do país, os autores analisaram 420 cadernetas, e dessas, apenas $111(25,5 \%)$ tinham preenchimento satisfatório. A partir desse resultado, foi possível verificar que o não preenchimento do documento esteve relacionado com o cuidador principal, quando esse não eram os pais ou avós, possuía escolaridade menor que nove anos, a mãe não havia realizado o pré-natal, ou não fez o acompanhamento pelo Sistema Único de Saúde (SUS), e entre os cuidadores que não receberam orientações sobre a importância da caderneta.

O índice que mostra maior preenchimento é o referente às vacinas com 99,3\% (FREITAS et al 2019). Corroborado por Amorin et al (2018b) o índice de menor preenchimento foi referente ao desenvolvimento neuropsicomotor. Freitas et al (2019) ressaltou que orientações referentes ao uso da caderneta foram ofertadas para pouco mais da metade dos responsáveis pela criança e com maior realização pelos profissionais da enfermagem. Referente a isto, Lima et al (2016) sustenta a oferta de orientações quanto ao uso da CSC, levando assim as mães a levarem mais as cadernetas no atendimento. 


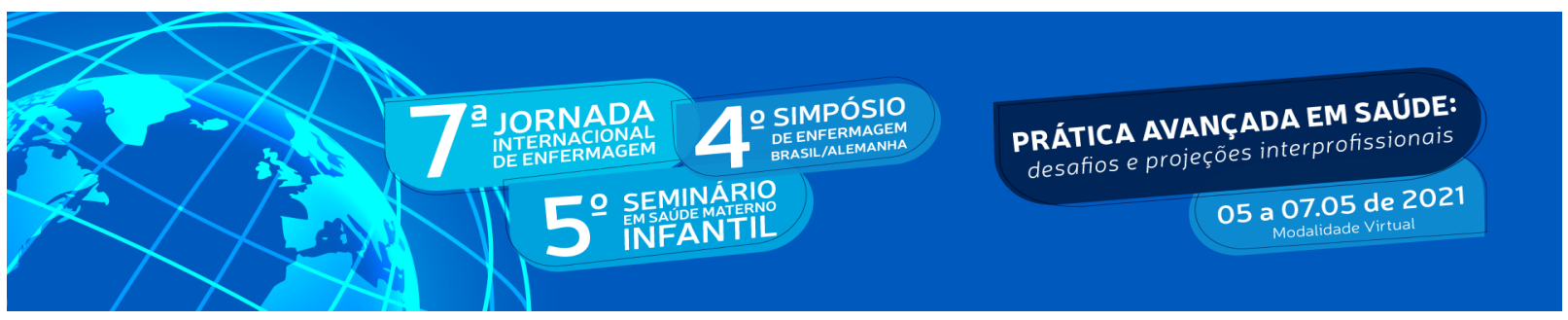

Cabe salientar que por ser entregue na maternidade, as orientações da CSC devem ser realizadas pelos profissionais salientando a importância do preenchimento da mesma. Entretanto, o que ocorre, por vezes, é o descaso por parte dos profissionais e a não orientação para mãe e/ou cuidadores da criança a realizarem as anotações. Esta falta reflete no prestígio da família como produtora do cuidado, reforçando o modelo biomédico de fazer saúde, onde somente o profissional tem autonomia para delegar e julgar informações acerca da criança, não reconhecendo que os cuidados em saúde podem estar sendo representados também pela família. (AMORIM et al, 2018a).

Frente a isso, Amorin et al (2018b) e Souza et al (2019), destacam que os registros na maternidade foram consideravelmente mais preenchidos do que na Atenção Primária à Saúde (APS) /outros serviços. Nesse ponto de vista, os resultados indicam que possui distinção no reconhecimento, pelos pais e profissionais, salientando um despreparo dos gestores de saúde na troca de saberes com os familiares, preconizando a necessidade de maior capacitação dos mesmos. Ademais, na ASP/outros serviços, a CSC depende dos pais a levarem, demonstrando que nos primeiros anos de vida há uma participação mais ativa dos genitores nos cuidados com a criança.

Outro estudo selecionado, como o de Vieira et al (2016), que também investigou sobre o preenchimento da CSC pelos profissionais de saúde percebeu que as crianças moradoras nos bairros com o Programa de Agentes Comunitários de Saúde (PACS) ou Estratégia de Saúde da Família (ESF), demonstraram maiores taxas de preenchimento das CSC quando conferidas àquelas atendidas na Unidade Básica em Saúde (UBS). Bem como, constatou-se que, independente da região do Brasil, onde o estudo foi desenvolvido, ocorreu baixo preenchimento da CSC pelos profissionais de saúde.

Conforme estudos de Silva, Cursino e Silva (2018), os motivos que intervêm no déficit para manejo da CSC, visando a vigilância do processo de crescimento e desenvolvimento da criança, são: a falta e a precariedade do preenchimento; A obscuridade na compreensão da importância do registro e a falta do conhecimento dos colaboradores acerca da caderneta; Aumento da procura no atendimento infantil; Precariedade na comunicação entre a equipe; Importância da presença do responsável no procedimento; Precariedade na orientação aos familiares sobre os cuidados referente à criança. 


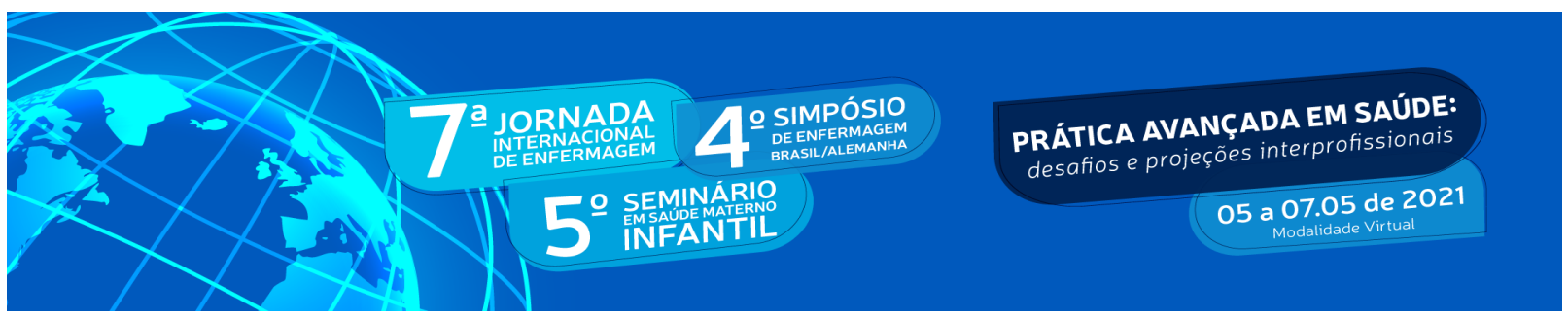

Segundo estudos de Almeida et al (2017), contribui para o raciocínio perante a veracidade dos dados apontados na CSC, realizado pelos colaboradores de saúde, ilustrando a relevância que possui o documento na assistência do desenvolvimento e crescimento infantil. Os colaboradores de saúde têm de verificar o preenchimento apropriado dessa ferramenta, no período da consulta de puericultura, para que possa garantir com segurança os registros, que irão amparar como referência na supervisão da saúde do infante, de preferência para comunidade de número expressivo à vulnerabilidade social.

Segundo Amorim et al (2018a) o uso efetivo da CSC tende a passar por um aprimoramento do instrumento, tanto na adequação de linguagem e forma, que visa maior entendimento por parte da família, como também viabilizando o registro de informações pelos profissionais presentes no serviço; evento este se tornará realidade a partir de capacitações com os profissionais da saúde que possuem um papel fundamental na promoção da saúde, ou seja, na utilização plena da caderneta, para que esta seja de fato um instrumento de vigilância, comunicação, educação e promoção da saúde.

\section{CONCLUSÃO}

Considera-se satisfatória a realização desta revisão de literatura, pois a partir dela foi possível evidenciar a produção científica acerca do preenchimento da CSC. Se fez evidente a necessidade de maior discussão e resgate com os profissionais sobre a importância do documento, para que assim possam estar realizando o que foi proposto desde a sua criação, ampliando o acesso à saúde e promovendo a coordenação e monitoramento do cuidado em saúde da criança.

A busca por um maior entendimento da CSC se mostra crucial, pois dentre os artigos estudados o que se fez prevalente foi o preenchimento insatisfatório e/ou de forma incorreta da caderneta, mostrando uma fragilidade no conhecimento acerca do seu uso por parte dos profissionais, carência de orientações para as famílias e percepção da CSC como cartão de vacina. Dessa maneira, informações importantes acerca do crescimento e desenvolvimento infantil perdem-se e não há o compartilhamento desses dados entre profissionais, o que gera uma ruptura no cuidado integral da saúde da criança. 


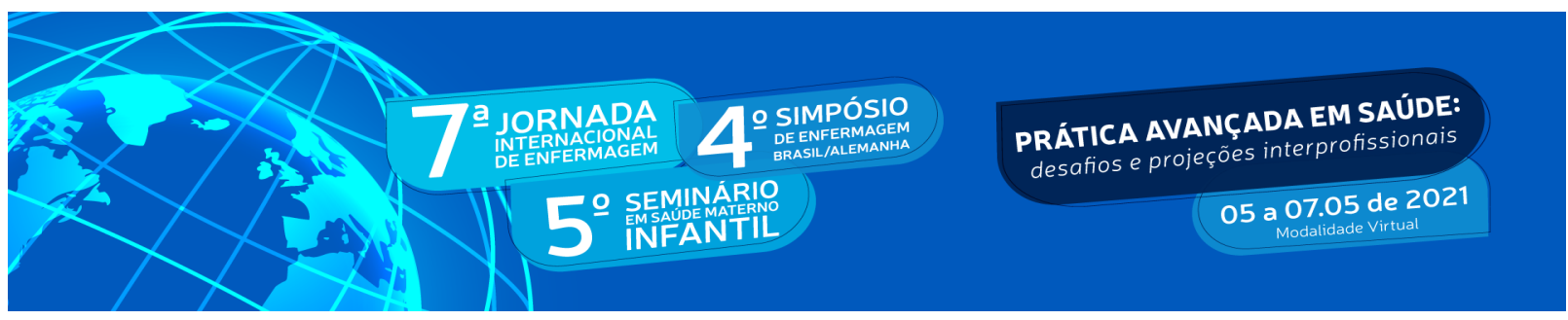

Em suma, a revisão narrativa possibilitou identificar as publicações sobre a CSC, promovendo o despertar para estratégias necessárias no aprimoramento do uso desse documento. Dentre essas estratégias, constatou-se que é necessário ascender capacitações para os profissionais de saúde, a fim de compreenderem a importância do seu uso. Assim, refletindo nas orientações para os familiares durante a entrega na maternidade até o acompanhamento em consultas nos demais serviços.

\section{REFERÊNCIAS}

ABUD S.M; GAIVA M.A.M. Registro dos dados de crescimento e desenvolvimento na caderneta de saúde da criança. Rev. Gaúcha Enferm, Porto Alegre, v. 36, n. 2, p.97-105, jun. 2015. Disponível em:

$<\mathrm{http}: / /$ www.scielo.br/scielo.php?script=sci_arttext\&pid=S1983-14472015000200097\&lng=p t\&nrm=iso $>$. Acesso em: 11 mar. 2021. https://doi.org/10.1590/1983-1447.2015.02.48427.

ALMEIDA, A. P. et al. O registro do crescimento e desenvolvimento da criança na caderneta de saúde. Rev. Enf. UERJ, v. 25, p. e16895, ago. 2017. Disponível em:

$<$ https://www.e-publicacoes.uerj.br/index.php/enfermagemuerj/article/view/16895>. Acesso em: 05 mar. 2021. ISSN 0104-3552. doi:https://doi.org/10.12957/reuerj.2017.16895.

AMORIM, L. P. et al. Avaliação do preenchimento da Caderneta de Saúde da Criança e qualidade do preenchimento segundo o tipo de serviço de saúde usado pela criança. Ciênc. saúde coletiva, Rio de Janeiro, v. 23, n. 2, p. 585-597, Fev. 2018a . Disponível em: $<$ http://www.scielo.br/scielo.php?script=sci_arttext\&pid=S1413-81232018000200585\&lng=e n\&nrm=iso $>$. Acesso em: 06 Mar. 2021.

https://doi.org/10.1590/1413-81232018232.06962016.

AMORIM, L. P. et al. Preenchimento da Caderneta de Saúde da Criança nos serviços de saúde em Belo Horizonte, Minas Gerais, Brasil. Epidemiol. Serv. Saúde, Brasília, v. 27, n. 1, e201701116, 2018b. Disponível em:

$<$ http://www.scielo.br/scielo.php?script=sci_arttext\&pid=S2237-96222018000100308\&lng=e n\&nrm=iso>. Acesso em: 23 fev. 2021.

ANDRADE G.N; REZENDE T.M.R.L; MADEIRA A.M.F. Caderneta de Saúde da Criança: experiências dos profissionais da atenção primária à saúde. Rev. esc. enferm. da USP, São Paulo, v. 48, n. 5. p. 857-864, out. 2014. Disponível em:

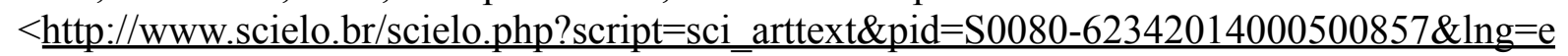
$\underline{\mathrm{n} \& \mathrm{nrm}=\mathrm{iso}}>$. Acesso em: 05 mar. 2021.

https://doi.org/10.1590/S0080-6234201400005000012.

BRANQUINHO, I. D.; LANZA, F. M.. Saúde da criança na atenção primária: evolução das políticas brasileiras e a atuação do enfermeiro. Rev. Enf. do Centro Oeste Mineiro, São João 


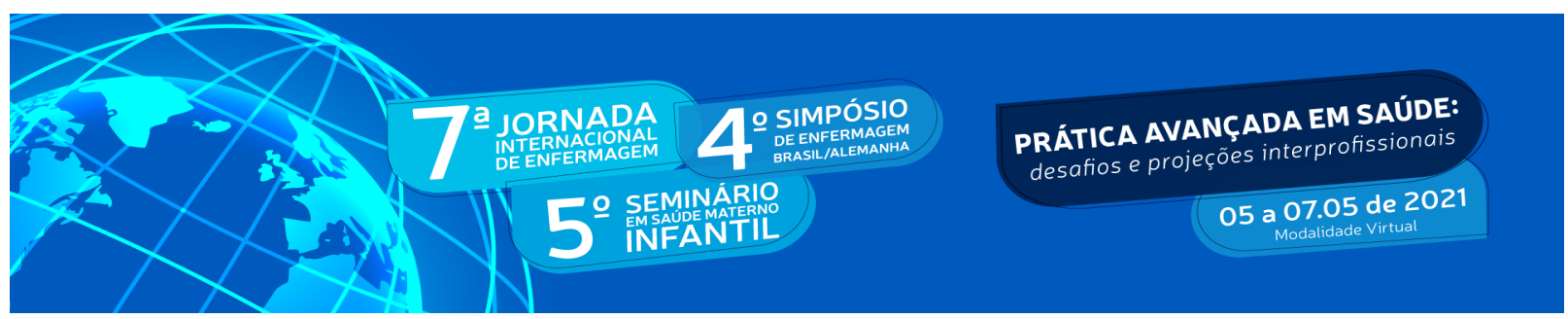

del-Rei, v. 8, n. 2753, p. 1-2, jul./2018. Disponível em:

$<$ http://seer.ufsj.edu.br/index.php/recom/article/view/2753>. Acesso em: 10 mar. 2020.

BRASIL. Política Nacional de Atenção Integral à Saúde da Criança: Orientações para implementação. $1^{\text {o }}$ ed. eletrônica. Brasília: Ministério da Saúde - DF; 2018. p. 1-184.

Disponível em:

$<$ https://portaldeboaspraticas.iff.fiocruz.br/wp-content/uploads/2018/07/Pol\%C3\%ADtica-Na cional-de-Aten $\% \mathrm{C} 3 \% \mathrm{~A} 7 \% \mathrm{C} 3 \% \mathrm{~A} 30-$ Integral- $\% \mathrm{C} 3 \% \mathrm{~A} 0-\mathrm{Sa} \% \mathrm{C} 3 \% \mathrm{BAde}$-da-Crian $\% \mathrm{C} 3 \% \mathrm{~A} 7 \mathrm{a}-$ PNAISC-Vers\%C3\%A3o-Eletr\%C3\%B4nica.pdf>. Acesso em: 16 fev. 2021.

CAMINHA, M. F. C. et al. Vigilância e desenvolvimento infantil: Análise da situação brasileira. Rev. paul. pediatr. vol.35 n.1, p 102-109, São Paulo Jan./Mar. 2017. Disponível em:

$<\underline{\text { http://www.scielo.br/scielo.php?script=sci arttext\&pid }=\text { S0103-05822017000100102\&lng }=\mathrm{e}}$ n\&nrm=iso > . Acesso em: 06 Mar. 2021.

https://doi.org/10.1590/1984-0462/;2017;35;1;00009.

FREITAS, J. L. G. et al. Preenchimento da caderneta de saúde da criança na primeira infância. Revista Brasileira em Promoção da Saúde, Porto Velho, Roraima, v. 32, n. 8407, p. 1-10, jan./2019. Disponível em: <https://periodicos.unifor.br/RBPS/article/view/8407>. Acesso em: 20 fev. 2021.

LEAL, M. C. et al. Saúde reprodutiva, materna, neonatal e infantil nos 30 anos do Sistema Único de Saúde (SUS). Ciência \& Saúde Coletiva [online]. 2018, v. 23, n. 6 , pp. 1915-1928. ISSN 1678-4561. https://doi.org/10.1590/1413-81232018236.03942018. Disponível em: $<$ https://doi.org/10.1590/1413-81232018236.03942018>. Acesso em: 10 mar 2021.

LIMA, L. G. et al. A Utilização da Caderneta de Saúde da Criança no acompanhamento Infantil. Revista Brasileira de Ciências da Saúde, Fortaleza, Ceará, v. 20, n. 2, p. 167-174, mai./2016. Disponível

em: $<$ https://portaldeboaspraticas.iff.fiocruz.br/wp-content/uploads/2019/09/21266-65405-1-P B.pdf $>$. Acesso em: 20 fev. 2021.

REICHERT, A. P. S. et al. Vigilância do crescimento e desenvolvimento: análise dos registros na caderneta de saúde da criança. Cogitare Enfermagem, [S.1.], v. 21, n. 4, dez.. 2016. ISSN 2176-9133. Disponível em: <https://revistas.ufpr.br/cogitare/article/view/45256>. Acesso em: 11 mar. 2021. doi:http://dx.doi.org/10.5380/ce.v21i4.45256.

ROSOLEM, L. H. et al. Caderneta de saúde da criança: coordenação do cuidado e acesso à saúde. Cogitare Enfermagem, [S.1.], v. 24, july 2019. ISSN 2176-9133. Disponível em: $<$ https://revistas.ufpr.br/cogitare/article/view/61496>. Acesso em: 11 mar. 2021. doi:http://dx.doi.org/10.5380/ce.v24i0.61496.

SALLES, I. C.; TORIYAMA, A. T. M. A Utilização da Caderneta de Saúde da Criança por Alunos de Enfermagem. Revista de Graduação USP, [S. l.], v. 2, n. 2, p. 41-46, 2017. DOI: 


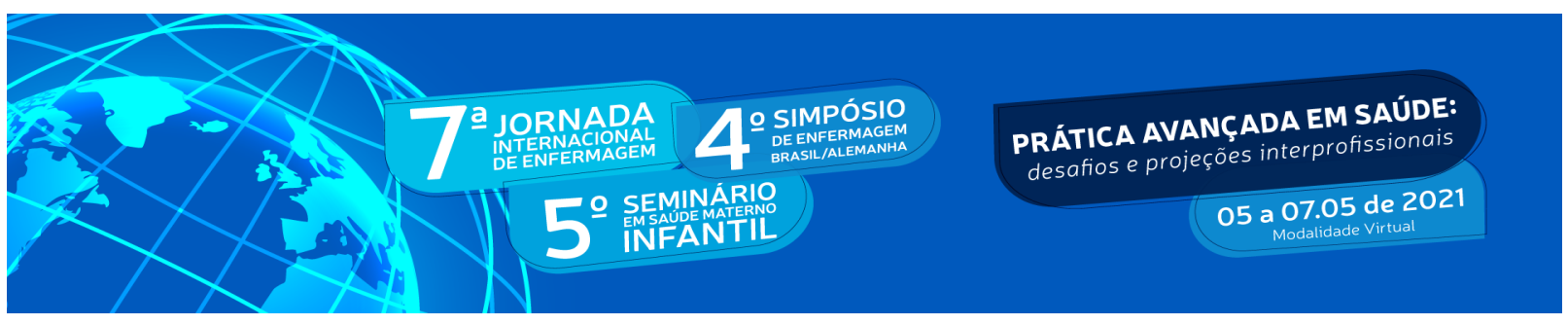

10.11606/issn.2525-376X.v2i2p41-46. Disponível em:

https://www.revistas.usp.br/gradmais/article/view/123882. Acesso em: 11 mar. 2021.

SILVA T.C.T D.A; CURSINO E.G; SILVA L.F. D.A. Caderneta de saúde da criança: Vigilância do crescimento e desenvolvimento infantil. Rev enferm UFPE on line., Recife, 12(12):3445-55, dez., 2018. Disponível em:

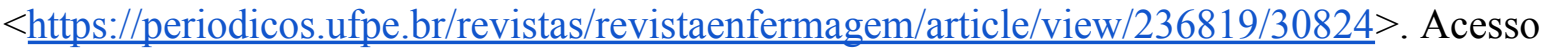
em: 06 mar. 2021.

SOUZA, N. S. et al. Vigilância e estímulo do crescimento e desenvolvimento infantil. Rev enferm UFPE on line, [ S.1.], v. 3, p. 680-689, Recife, mar., 2019. ISSN: 1981-8963.

Disponível em: < https://periodicos.ufpe.br/revistas/revistaenfermagem/article/view/238634>. Acesso em: 11 mar. 2021. Doi:

https://doi.org/10.5205/1981-8963-v13i3a238634p680-689-2019.

VIEIRA, G. O. et al . Fatores associados ao uso da Caderneta de Saúde da Criança em uma cidade de grande porte do nordeste brasileiro, 2009. Ciênc. saúde coletiva, Rio de Janeiro, v. 22, n. 6, p. 1943-1954, Junho 2017 . Disponível em:

$<$ http://www.scielo.br/scielo.php?script=sci_arttext\&pid=S1413-81232017002601943\&lng=e n\&nrm=iso $>$. Acesso em: 22 fev. 2021. 